\title{
Simulation and Analysis of PMSG-based Wind Energy Conversion System using Different Coverter Models
}

\author{
Hua Ye ${ }^{1}$, Juan $\mathrm{Su}^{1}$, Songhuai $\mathrm{Du}^{2}$ \\ ${ }^{1}$ SENSE Lab, Technical University of Berlin, Berlin, Germany \\ ${ }^{2}$ Department of Electrical Engineering, China Agricultural University, Beijing, China \\ Email: yehua_tub@hotmail.com
}

Received 2013

\begin{abstract}
Modeling of a permanent magnet synchronous generator (PMSG)-based wind energy conversion system is presented for the simulation of diverse transients. In order to perform multi-scale transients, the back-to-back voltage source converter (VSC) is modeled using three different forms including the detailed, switched and average models. The PMSG-based WECS is implemented in PSCAD/EMTDC. The simulation results show that the detailed and switched model of VSC give a detailed and accurate representation, while the average model provides an efficient simulation.
\end{abstract}

Keywords: Power system simulation, PMSG, Wind power generation, Voltage source converter, Multi-scale transients

\section{Introduction}

Modeling and simulation is an essential step for the design and operation of modern power systems including distributed energy resources. As a result of increasing environmental concern, wind energy conversion system (WECS) is becoming the most competitive form of electricity generation from renewable sources. Within concepts of WECS, the permanent magnet synchronous generator (PMSG)-based direct driven WECS has advantages over the other concepts in terms of the energy yield, reliability and maintenance problem [1].

Usually, a PMSG-based WECS is composed of mechanical, electrical, and control subsystems whose time constants vary from microseconds to minutes or even more. For example, power electronic converter performs high-frequency transients due to its high-frequency switching. At the same time, the dynamic behavior of the wind turbine shows a slow change. The use of detailed switching models often leads to significant increase of computational times. On the contract, the power system dynamic simulation does not account for fast transients and harmonics.

A typical schematic representation of this wind power generation system is depicted in Figure 1. The PMSG is connected at the point of common coupling (PCC) to the utility grid via a back-to-back two-level voltage source converter (VSC) and a step-up transformer. For purpose of analysis, the PMSG-based WECS is divided into two parts. The back-to-back VSC presents the high-frequency transients, which is hatched in a shadow. The rest part of this system is considered as slow part presenting low-frequency transients.

In this paper, modeling and simulation of the components in this PMSG-based WECS is developed. In order to analyze mulit-scale transients, three alternative forms of the VSC using the detailed, switched [2] and average models [3] are represented. Through the simulator PSCAD/EMTDC, this PMSG-based WECS is implemented by employing different models of the VSC.

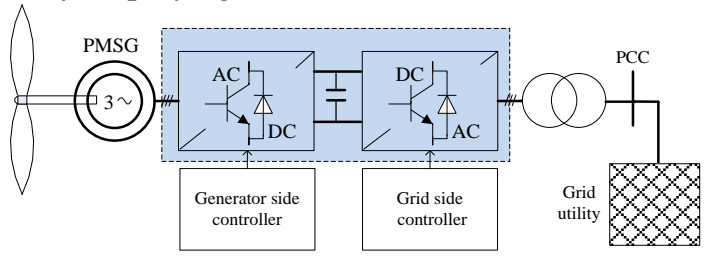

Figure 1. The schematic representation of a PMSG-based WECS unit.

This paper is organized as follows. A PMSG-based WECS is described in Section II. In Section III, three different models of VSC are represented and compared. A test case is performed in Section IV. Conclusions are drawn in Section $\mathrm{V}$

\section{PMSG-based Wind Power Conversion System}

\subsection{Aerodynamic and Mechanical systems}

The operational performance of wind turbine can be 
modeled through a mathematical relation between the wind speed $V_{\mathrm{w}}$ and mechanical power extracted as follows:

$$
P_{\mathrm{wt}}=0.5 \rho \pi r^{2} V_{\mathrm{w}}^{3} C_{\mathrm{p}}(\lambda, \beta)
$$

where $P_{\mathrm{wt}}$ is the extracted power from the wind, $\rho$ is the air density, $r$ is the blade radius, and $C_{\mathrm{p}}$ is the power coefficient which is a function of both tip speed ratio, $\lambda$ and blade pitch angle, $\beta$.

Numerical approximations have been developed to calculate $C_{\mathrm{p}}$ as follows:

$$
C_{\mathrm{p}}(\lambda, \beta)=0.5176\left(\frac{116}{\lambda_{i}}-0.4 \beta-5\right) \mathrm{e}^{\frac{-21}{\lambda_{i}}}+0.0068 \lambda \text {, }
$$

with

$$
\frac{1}{\lambda_{i}}=\frac{1}{\lambda+0.08 \beta}-\frac{0.035}{\beta^{3}+1} .
$$

If the air density and blade swept area are invariable, $P_{\text {wt }}$ depends on the tip speed ratio and the turbine speed. The maximum output power of the wind turbine is calculated at the maximum power conversion coefficient $C_{\mathrm{p} \max }$ and the optimal tip speed ratio $\lambda_{\text {opt }}$ :

$$
P_{\text {wt max }}=0.5 \rho \pi r^{2} C_{\mathrm{p} \max }\left(\frac{r \omega_{\mathrm{t}}}{\lambda_{\mathrm{opt}}}\right)^{3}=k_{\mathrm{opt}} \omega_{\mathrm{t}}^{3},
$$

where $k_{\text {opt }}=0.5 \rho \pi r^{2} C_{\mathrm{p} \max }\left(r / \lambda_{\text {opt }}\right)^{3}$, and $\omega_{\mathrm{t}}$ is the angular speed of the wind turbine blade. The maximum power is obtained by regulating the turbine speed with respected to the wind speed such that the maximum power point tracking (MPPT) can be achieved. The MPPT gives the reference power, $P_{\text {ref }}$, for the grid side converter discussed hereafter.

In recent years, direct-driven PMSG has gained considerable interest due to its advantages including no gear maintenance, reliability and efficient energy production. Thus, analysis of dynamic characteristics of the driven-train is becoming a concern of utmost importance. In this paper, the driven-train is represented by one-mass model:

$$
J \frac{\mathrm{d} \omega_{\mathrm{t}}(t)}{\mathrm{d} t}=T_{\mathrm{wt}}(t)-T_{\mathrm{g}}(t)
$$

where $J$ is the combined inertia of turbine and generator, $T_{\mathrm{wt}}$ is the aerodynamic torque produced by the turbine, and $T_{\mathrm{g}}$ is the electrical torque.

\subsection{PMSG Representation}

The computations associated with the PMSG modeling in $a b c$ reference frame are complicated and lengthy. Usually, the $d q 0$ or Park transformation is applied in the PMSG modeling. The electromagnetic equations of PMSG are described based on the $d q 0$ reference frame in which the $q$ axis rotates synchronously with the magnet flux $\psi_{\mathrm{f}}$ as follows:

$$
\begin{aligned}
& L_{\mathrm{sd}} \frac{\mathrm{d} i_{\mathrm{sd}}(t)}{\mathrm{d} t}=v_{\mathrm{sd}}(t)-R_{\mathrm{s}} i_{\mathrm{sd}}(t)+\omega_{\mathrm{g}}(t) L_{\mathrm{sq}} i_{\mathrm{sq}}(t), \\
& L_{\mathrm{sq}} \frac{\mathrm{d} i_{\mathrm{sq}}(t)}{\mathrm{d} t}=v_{\mathrm{sq}}(t)-R_{\mathrm{s}} i_{\mathrm{sq}}(t)+\omega_{\mathrm{g}}(t) L_{\mathrm{sd}} i_{\mathrm{sq}}(t)-\omega_{\mathrm{g}}(t) \psi_{\mathrm{f}},
\end{aligned}
$$

where $L_{\mathrm{sd}}, L_{\mathrm{sq}}$ and $R_{\mathrm{s}}$ are the generator inductances and resistance, respectively. $\omega_{\mathrm{g}}$ is the angular speed of the generator.

\subsection{Control System}

1) Generator-side controller: the control strategies applied to the generator-side converter is schematically expressed in Figure 2, where the direct current vector control mechanism is adopted. The terminal currents of the PMSG are used as input signals to the generator-side controller.

As one of the salient features, the DC-link voltage is controlled by the generator-side controller instead of the grid-side controller. When a network disturbance occurs, the controller keeps the generated active power of PMSG at the appropriate level to avoid DC-link overvoltage. Meanwhile, the reference of d-axis current is set to zero to avoid the demagnetization of permanent magnetic. The corresponding reactive power output of PMSG is zero.

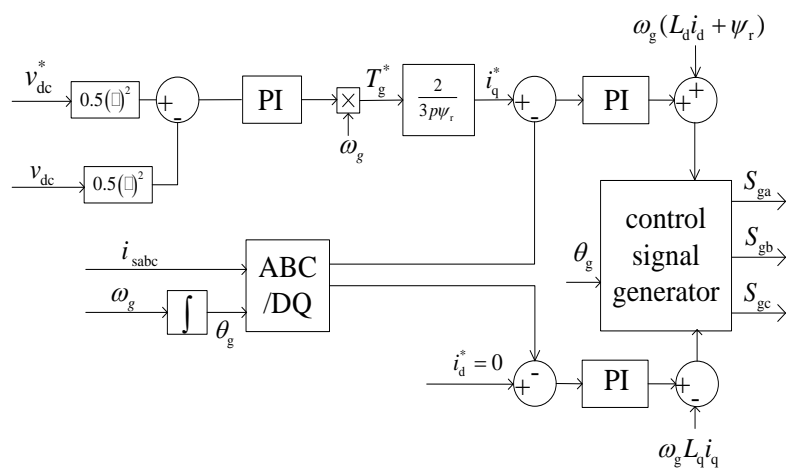

Figure 2. Control block for the generator-side converter.

2) Grid-side controller: the block diagram of the grid-side controller is shown in Figure 3. The direct current vector control mechanism is also adopted for the control design.

The active power reference $P_{\text {ref }}$ is determined in such a way to provide the maximum power to the grid through the MPPT as mentioned earlier. In this study, $P_{\text {ref }}$ varies depending on the level of terminal voltage during the times when the voltage drops below 0.9 p.u. This situation is used to supply appropriate power to the grid when a network disturbance appears. Meanwhile, it can avoid the overvoltage in the DC-link circuit. 


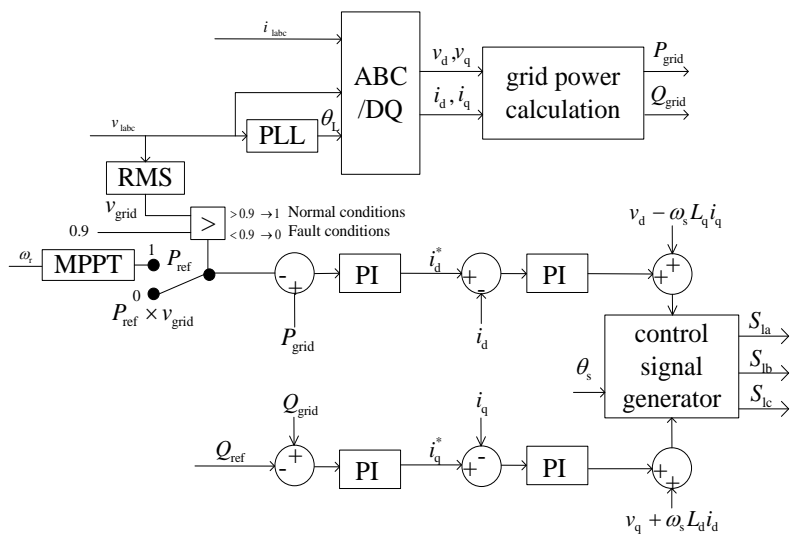

Figure 3. Block diagram of the grid-side controller.

\section{Three Different Models of AC-DC-AC Voltage Source Converter}

In PMSG-based WECS, a back-to-back VSC is usually used to link the direct drive synchronous generator and the utility grid. The response of such power electronic converter to a disturbance is characterized by very high frequency phenomena. In spite of this, due to the objective of different studies, a voltage source converter is currently modeled with different ways in power system simulations. The topology of the back-to-back VSC comprises a double conversion from AC to DC and then from DC to AC. For the sake of analysis, only generator-side VSC is represented in the following, and the grid-side VSC is developed in an analogous way.

\subsection{Detailed Model}

In this case, the ac-to-ac converter is schematically expressed by using actual power semiconductor device models. As shown in Figure 4, this detailed model is composed of 6 IGBTs and 6 anti-parallel diodes. Since the simulation is mainly performed at the circuit level, a very detailed presentation of the back-to-back VSC can be obtained. For instance, the harmonics generated by the VSC can be precisely represented. This is instructive for the production design associated with the wind power generation.

However, these models in some simulator like Pspice are described as a nonlinear controlled source by means of functions that contain exponential terms. It results slow execution times, large amounts of generated data, and convergence problem [4]. Based on the circuit configuration, the modeling in Matlab Simulink involves differential equations that are resolved through state space method. From the viewpoint of wind farm, a large number of differential equations exist, and thus the computations are cumbersome and time-consuming.

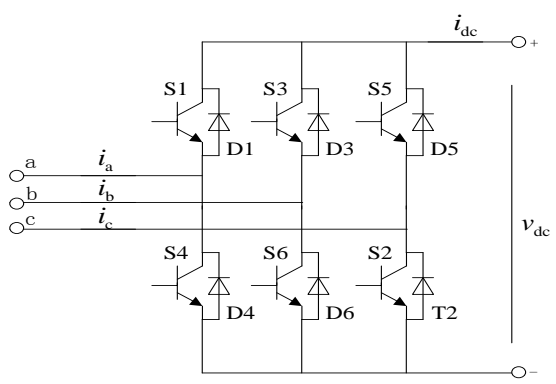

Figure 4. VSC configuration.

\subsection{Switched Model}

The switching function concept is used to describe the performance of the actual power converters. As a result, the ac-to-ac converter is modeled according to the functions rather than circuit topologies [2]. Since it does not refer to single switch element, the switching can be easily modeled.

Figure 5 shows an equivalent model where switches are replaced by three voltage sources on ac side and a current source on dc side. The voltage sources are a function of the DC-link voltage $v_{\mathrm{dc}}$ and the switching functions.

$$
\left[\begin{array}{c}
v_{\mathrm{ga}} \\
v_{\mathrm{gb}} \\
v_{\mathrm{gc}}
\end{array}\right]=\frac{1}{3} v_{\mathrm{dc}}\left[\begin{array}{rrr}
2 & -1 & -1 \\
-1 & 2 & -1 \\
-1 & -1 & 2
\end{array}\right]\left[\begin{array}{c}
s_{\mathrm{ga}} \\
S_{\mathrm{gb}} \\
S_{\mathrm{gc}}
\end{array}\right],
$$

where $s_{\mathrm{ga}}, s_{\mathrm{gb}}$ and $s_{\mathrm{gc}}$ are the switching functions that uses the 6 IGBT pulses as control input. Herein, the sinusoidal pulse-width-modulation (SPWM) control strategies are used to generate the IGBT pulses. The DC-link current source is defined as a function of the ac side currents and the switching functions:

$$
i_{\mathrm{dc}}=\left[\begin{array}{lll}
s_{\mathrm{ga}} & S_{\mathrm{gb}} & s_{\mathrm{gc}}
\end{array}\right]\left[\begin{array}{l}
i_{\mathrm{a}} \\
i_{\mathrm{b}} \\
i_{\mathrm{c}}
\end{array}\right] .
$$

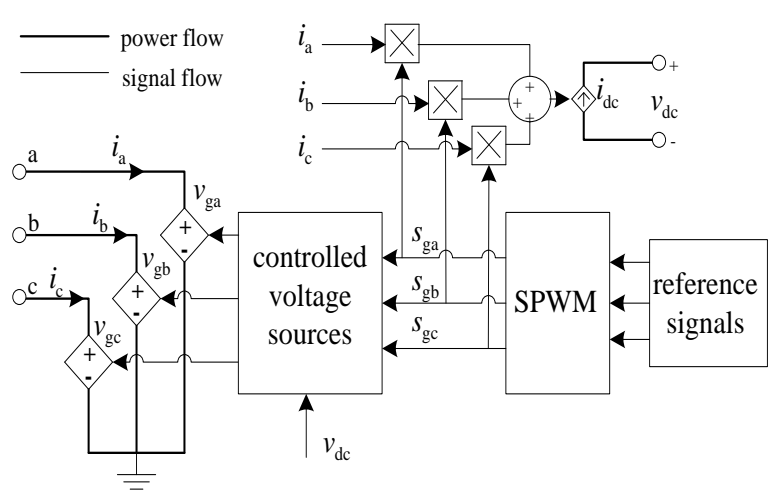

Figure 5. Switching function model of VSC. 
The switched model can correctly represent the main components of the electromagnetic transients and harmonics generated by the VSC. The switching frequency of VSC can reach several $\mathrm{kHz}$, and thus a small time step size in the order of microseconds is used in the simulation. This is not suitable for power system dynamic simulation studies. Therefore, a low-frequency representation of the behavior of the converter is required.

\subsection{Average Model}

Figure 6 presents an average model of the VSC. The three reference signals replacing the switching functions are used to represent three average voltage sources on ac side. Correspondingly, the current source is calculated based on power balance by neglecting the internal loss of VSC.

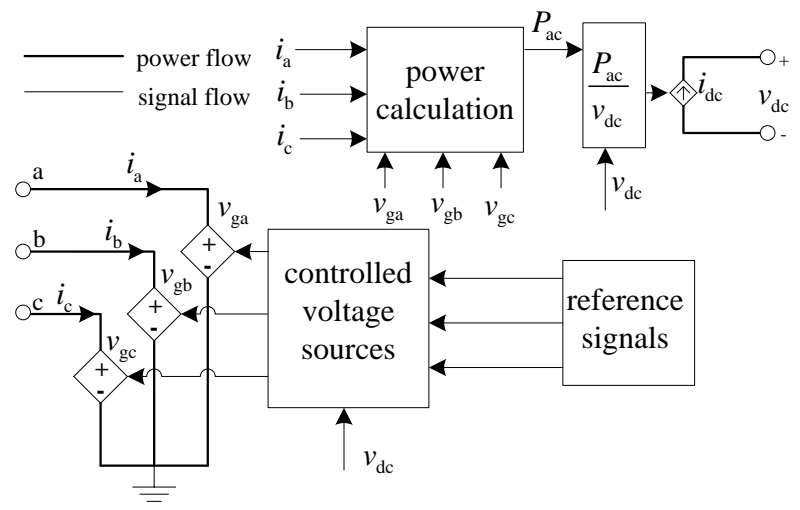

Figure 6. Average model of VSC.

This average model is well suitable for the simulation of slow transients [5]. A large time step can be used so that much more efficient simulation is achieved. However, this model does not represent high-frequency transients and harmonics.

\section{Test Case Studies}

A PMSG-based WECS is simulated and analyzed when subjected to the system faults. Figure 7 shows the PMSG-based wind power unit connected to the utility grid via a step-up transformer and transmission line. This PMSG-based WECS was implemented in PSCAD/EMTDC, where the above three different converter models are used separately for the purpose of comparison.

The grid operation under various conditions has a significant impact on the wind power generation. In this study, it is of prime interest to investigate the low voltage ride through (LVRT), which is critical to the design of the PMSG-based WECS. A three-phase-to-ground fault was applied to the middle of the transmission line, and it was self-cleared after $0.16 \mathrm{~s}$. For the sake of analysis, the wind speed is maintained constant at $10 \mathrm{~m} / \mathrm{s}$.

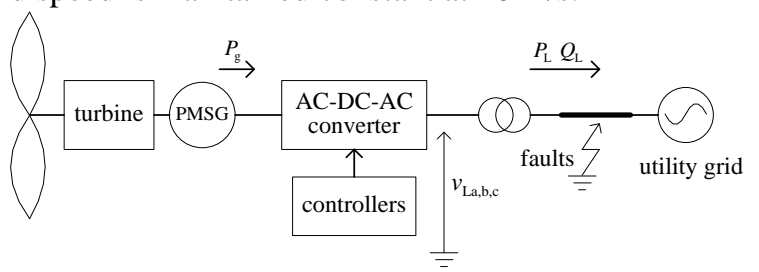

Figure 7. A PMSG-based wind power unit.

For the purpose of comparison, the following three alternative forms of representation of AC-DC-AC converter are included in the implementation of WECS separately.

- The detailed model;

- The switched model;

- The average model.

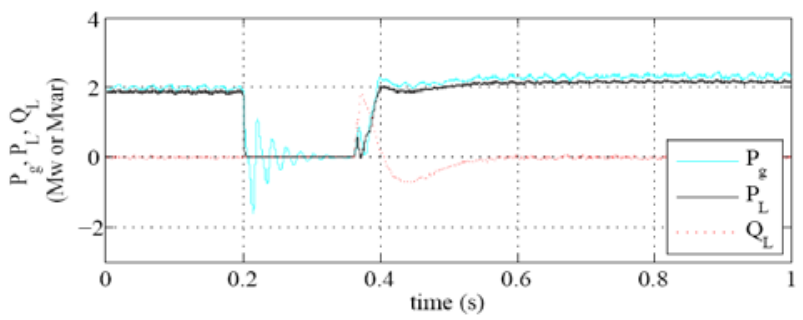

(a) Simulation using the detailed model of VSC

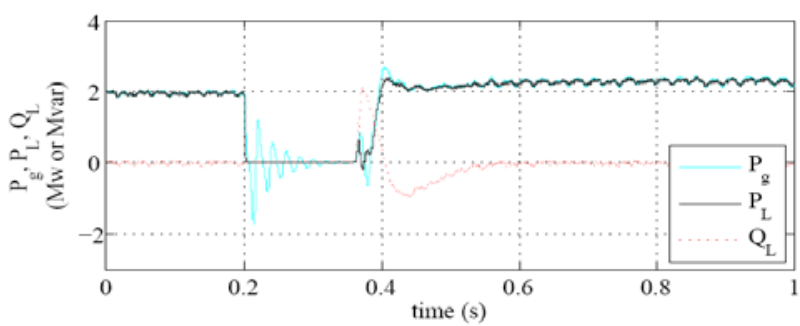

(b) Simulation using the switched model of VSC

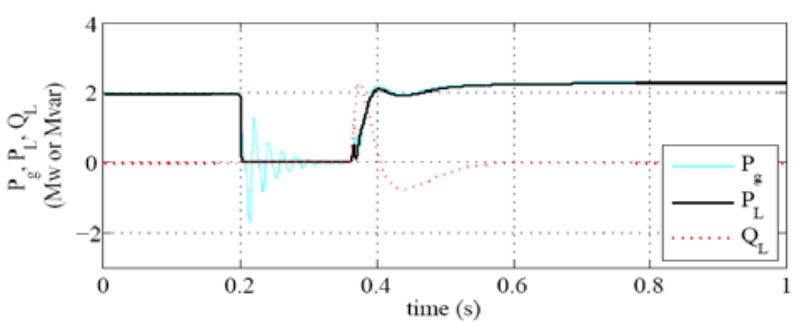

(c) Simulation using the average model of VSC

Figure 8. Active and reactive power produced by the PMSG-based WECS.

Figure 8 shows plots of the power produced from the PMSG, $P_{\mathrm{g}}$, and the real and reactive power injected into the utility grid, $P_{L}$ and $Q_{L}$. Plots in Figures 8(a)-8(c) are obtained from the above three alternatives, respec- 
tively. At $t=0.2 \mathrm{~s}$, a three-phase-to-ground fault occurred. Due to the generator-side controller, the PMSG output power keeps an agreement with the one required by the grid side. Hence, this can avoid the oscillation of DC-link voltage as shown in Figure 9. In Figure 8(a), the value of $P_{L}$ is lower than $P_{\mathrm{g}}$ as the internal loss of detailed model of the VSC is not neglected. As seen from these results, there are no visible differences using the three converter models.

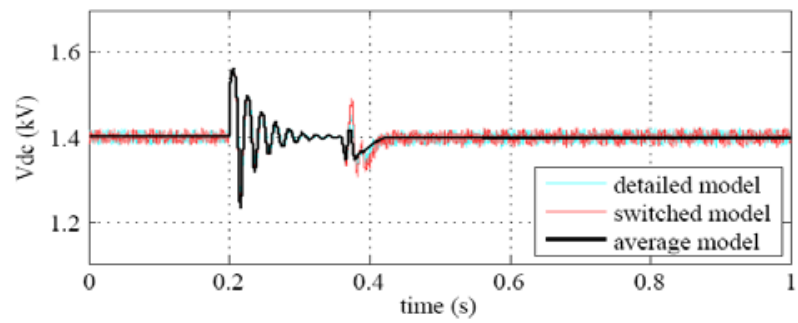

Figure 9. DC-link voltage.

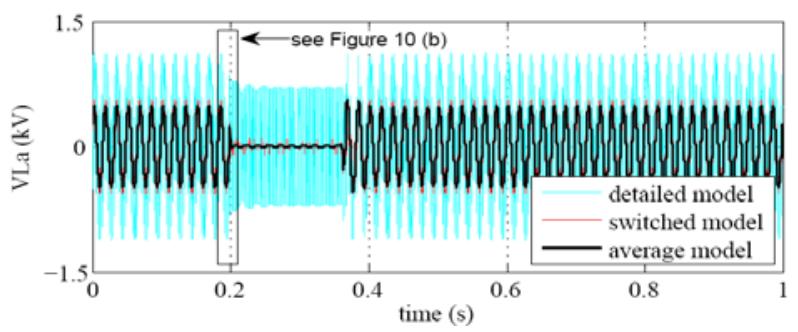

(a) Simulation using different models of VSC

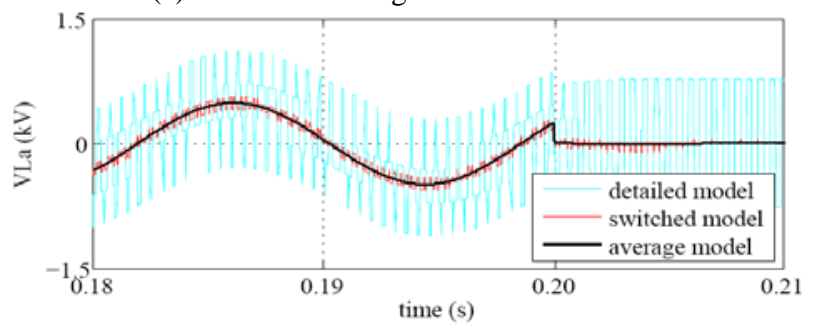

(b) Zoom-in results using different models of VSC

Figure 10. Grid-side VSC terminal voltage on ac side.

As shown in Figures 10 and 11, high-frequency transients such as harmonics are well represented using the detailed model of the VSC. However, the average model neglects the effect of fast switching and the small-signal characteristics are extracted. In order to evaluate simulation efficiency, the computational times using the above three different VSC models are summarized in Table I. Due to the detailed representation of circuit configuration, the computational time with the detailed model is greatly increased compared to the switched model with the same simulation time step. However, the average model provides significant savings in computational time compared to the other models.
Table 1. Comparison of simulation time using different VSC models.

\begin{tabular}{cccc}
\hline VSC models & $\begin{array}{c}\text { Detailed } \\
\text { model }\end{array}$ & $\begin{array}{c}\text { Switched } \\
\text { model }\end{array}$ & $\begin{array}{c}\text { Average } \\
\text { model }\end{array}$ \\
\hline Time step size & $20 \mu \mathrm{s}$ & $20 \mu \mathrm{s}$ & $200 \mu \mathrm{s}$ \\
\hline Compuational time & $35.5 \mathrm{~s}$ & $15.06 \mathrm{~s}$ & $1.45 \mathrm{~s}$ \\
\hline
\end{tabular}

\section{Conclusions}

Modeling of a PMSG-based WECS was presented for the accurate or efficient simulation of diverse transients. Each of the components covering the mechanical, electrical and control subsystems was modeled. Although the back-to-back VSC contains high-frequency transients occurring, the average VSC model was included for dynamics simulation leading to a high computational efficiency. In order to perform the high-frequency transients accurately, the detailed and switched models of VSC were used

This PMSG-based WECS was implemented in PSCAD/EMTDC using the detailed, switched and averaged models of VSC, respectively. The results shows that the detailed and switched models give accurate simulation, but have an increased computational cost. At the same time, the average model provides an efficient simulation, but does not give detailed simulation. Therefore, an innovative model is required to bridge the simulation of diverse transients in the same simulation run.

\section{REFERENCES}

[1] H. Li and Z. Chen, "Overview of different wind generator systems and their comparisons," IET Renewable Power Generation, 2(2):123-138, 2008. Vol. 2, No. 2, 2008, pp. 123-138.

[2] B. K. Lee and M. Ehsani, "A simplified functional simulation model for three-phase voltage-source inverter using switching function concept," IEEE Transactions on Industrial Electronics, Vol. 48, No. 2, 2001, pp. 309-321.

[3] S. Chiniforoosh, J. Jatskevic, A. Yaydani, V. Sood, V. Dinavahi, J. A. Martinez, and A. Ramirez, "Definitions and applications of dynamic average models for analysis of power systems," IEEE Transactions on Power Delivery, Vol. 25, No. 4, 2010, pp. 2655-2669.

[4] L. Salazar and G. Joos, "PSPICE simulation of three-phase inverters by means of switching functions," IEEE Transactions on Power Electronics, Vol. 9, No. 1, 1994, pp. 35-42.

[5] J. G. Slootweg, S. W. H. de Haan, H. Polinder and W. L Kling, "General model for representing variable speed wind turbines in power system dynamics simulaitons," IEEE Transactions on Power Systems, Vol. 18, No. 1, 2003, pp. 144-151. 